\title{
First Stage Solid Propellant Multiply Debris Thermal Analysis
}

\author{
Benjamin M. Toleman ${ }^{1}$ \\ United Space Alliance, Houston, TX, 77058
}

\begin{abstract}
Destruction of a solid rocket stage of a launch vehicle can create a thermal radiation hazard for an aborting crew module. This hazard was assessed for the Constellation Program (Cx) crew and launch vehicle concept. For this concept, if an abort was initiated in first stage flight, the Crew Module (CM) will separate and be pulled away from the malfunctioning launch vehicle via a Launch Abort System (LAS). Having aborted the mission, the launch vehicle will likely be destroyed via a Flight Termination System (FTS) in order to prevent it from errantly traversing back over land and posing a risk to the public. The resulting launch vehicle debris field, composed primarily of first stage solid propellant, poses a threat to the CM. The harsh radiative thermal environment, caused by surrounding burning propellant debris, may lead to CM parachute failure. A methodology, detailed herein, has been developed to address this concern and to quantify the risk of first stage propellant debris leading to the thermal demise of the $C M$ parachutes. Utilizing basic thermal radiation principles, a software program was developed to calculate parachute temperature as a function of time for a given abort trajectory and debris piece trajectory set. Two test cases, considered worst case aborts with regard to launch vehicle debris environments, were analyzed using the simulation: an abort declared at Mach 1 and an abort declared at maximum dynamic pressure (Max Q). For both cases, the resulting temperature profiles indicated that thermal limits for the parachutes were not exceeded. However, short duration close encounters by single debris pieces did have a significant effect on parachute temperature. Therefore while these two test cases did not indicate exceedance of thermal limits, in order to quantify the risk of parachute failure due to radiative effects from the abort environment, a more thorough probability-based analysis using the methodology demonstrated herein must be performed.
\end{abstract}

\section{Nomenclature}

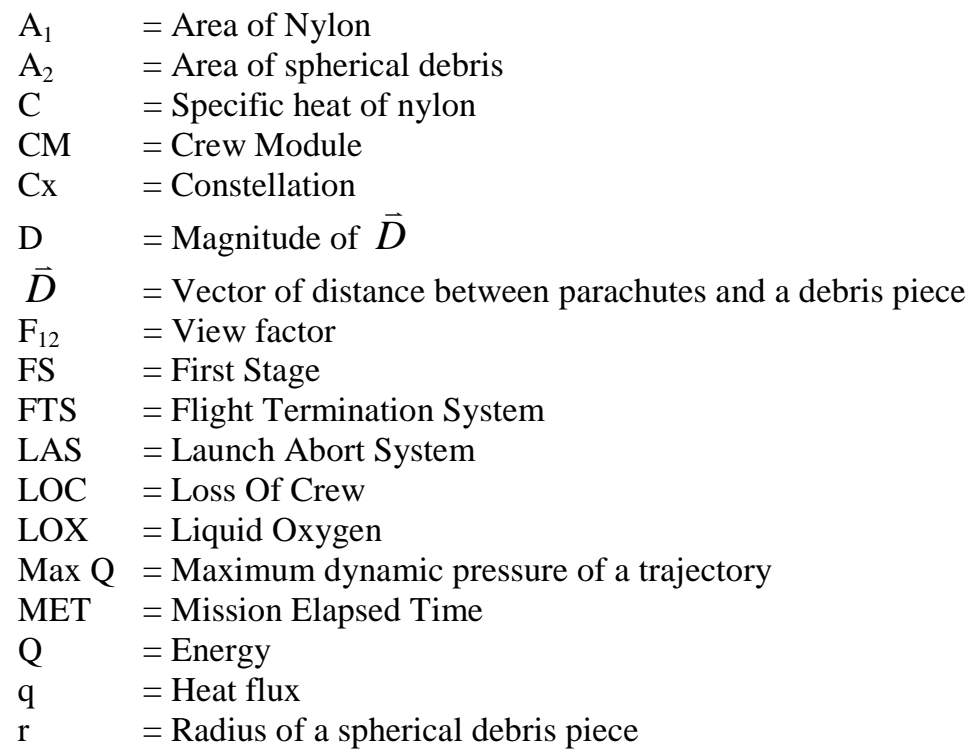

\footnotetext{
${ }^{1}$ Engineering Staff III, Ascent/Descent Flight Design, 600 Gemini Ave, Houston, TX, 77058
} 


$$
\begin{array}{ll}
\mathrm{T} & =\text { Temperature } \\
\varepsilon & =\text { Emissivity of parachutes } \\
\sigma & =\text { Stefan-Boltzmann Constant } \\
\rho_{\mathrm{N}} & =\text { Mass to Area ratio of the parachute nylon. } \\
\theta_{1} & =\text { Angle between normal vector of } \mathrm{A}_{1} \text { and the vector } \vec{D} \\
\theta_{2} & =\text { Angle between normal vector of } \mathrm{A}_{2} \text { and the vector } \vec{D}
\end{array}
$$

\section{Introduction}

A solid rocket stage on a launch vehicle can create a thermal radiation hazard for an aborting crew module. This hazard was assessed for Constellation's (Cx) Ares I launch vehicle and Orion crew vehicle. The propulsion system of Ares I consists of a first stage solid rocket motor and a liquid oxygen (LOX) and liquid hydrogen upper stage. If an abort is initiated during first stage flight, the Orion Launch Abort System (LAS) is fired to quickly pull the Orion Crew Module (CM) away from the launch vehicle in an effort to save the crew. During this abort there is an option to detonate the "headless" launch vehicle for public safety. Detonation of the Ares I results in thousands of fragments thrown outward from the destruct location. In such a scenario, there is a risk that launch vehicle debris could strike the CM and lead to a Loss Of Crew (LOC) event. The majority of these debris fragments originate from the first stage propulsion system and are comprised of burning solid rocket propellant. The risk of debris strikes in first stage abort scenarios have been studied in depth by the Cx Program. However, a secondary debris concern exists - the thermal effects of burning solid rocket propellant on the CM, and specifically on the parachute system.

An abort trajectory analysis on Ares I was performed using a first stage debris catalog, which utilizes a vehicle specific debris database to generate propellant debris characteristics. This debris database is a heritage-based/First Stage (FS) debris catalog. From this analysis we observed that aborts in the Mach 1 and maximum dynamic pressure (Max Q) regions could result in the CM being surrounded by debris for a significant portion of the abort trajectory. When the parachutes are deployed, there is a possibility of parachute failure from burn through. Therefore, a methodology was developed to calculate the CM parachute temperature profile for a given abort trajectory and a set of debris trajectories.

\section{Assumptions/Limitations}

To develop and test the validity of the methodology, several assumptions were made to simplify the problem. These assumptions, listed below, represent conservative conditions for the problem.

- The debris pieces are spherical and radiate as blackbodies.

- $\quad$ The ambient temperature $\left(\mathrm{T}_{\mathrm{amb}}\right)$ is $50^{\circ} \mathrm{F}(283 \mathrm{~K})$.

- The debris burns $\left(\mathrm{T}_{\text {fireball }}\right)$ at a constant $4000^{\circ} \mathrm{F}(2478 \mathrm{~K})$ through the entire abort trajectory.

- There is no heat transfer between debris, therefore all debris pieces are at the same temperature.

- Only radiative heating is analyzed; convective cooling is ignored.

The next set of assumptions is based on Ares I and Orion data, which were obtained from the Cx Program.

- The nylon parachutes have an emissivity $(\varepsilon)$ of 0.899 .

- The parachutes failure temperature is $150^{\circ} \mathrm{F}(339 \mathrm{~K})$.

- Debris density is $1811.1 \mathrm{~kg} / \mathrm{m}^{3}$ (used to determine debris size).

- The sample area of the parachute is, $\mathrm{A}_{1}=1.0\left[\mathrm{~m}^{2}\right]$.

- The Stefan-Boltzmann constant $(\sigma)$ is 5.669e-9 $\left[\mathrm{W} /\left(\mathrm{m}^{2} \mathrm{~K}^{4}\right)\right]$.

- The Specific Heat of nylon (C) is $1.7[\mathrm{~J} /(\mathrm{gK})]$.

- The density of nylon per square area $\left(\rho_{\mathrm{N}}\right)$ is $33.9049\left[\mathrm{~g} / \mathrm{m}^{2}\right]$

\section{Methodology}

The foundation of this methodology will be based on the Stefan-Boltzmann Law:

$$
q=\varepsilon \sigma T^{4} \text { (Ref. 3) }
$$

The problem is constructed as a three body system, as depicted in Fig. 1. The nylon (body 1) is a section of the parachute. The fireball (body 2) is the collection of burning debris. The third body is the portion of the sky that is not obscured by the fireball. Our approach was to analyze the heat flux absorbed and expelled by the nylon, by using 
the Stefan-Boltzmann Law to write two equations: one that represents the heat flux imparted to the nylon from the fireball, and one that represents the heat flux radiated out from the nylon to the sky:

$$
\begin{gathered}
q_{\text {in }}=\varepsilon \sigma\left(T_{\text {fireball }}^{4}-T_{\text {nylon }}^{4}\right) \\
q_{\text {in }}=\varepsilon \sigma\left(T_{\text {nylon }}^{4}-T_{\text {amb }}^{4}\right)
\end{gathered}
$$

Equation (2) assumes all of the radiated heat from the fireball is directed at the nylon. This is not the case, since the fireball is a 3D object that radiates in all directions. Equation (3) uses the same assumption, but corresponds to the relationship between the nylon and sky. To account for this assumption, Eq. (2) and Eq. (3) will need to be multiplied by a view factor. The view factor is. defined as "the fraction of radiation leaving one surface that is intercepted by a second surface." ${ }^{3}$ When relating several bodies, the summation rule applies: $F_{12}+F_{13}=1$. Applying the view factor and summation rule on Eq. (2) and Eq. (3) results in:

$$
\begin{gathered}
q_{\text {in }}=\varepsilon \sigma\left(T_{\text {fireball }}^{4}-T_{\text {nylon }}^{4}\right) F_{12} \\
q_{\text {out }}=\varepsilon \sigma\left(T_{\text {nylon }}^{4}-T_{\text {amb }}^{4}\right) F_{13} \rightarrow \\
q_{\text {out }}=\varepsilon \sigma\left(T_{\text {nylon }}^{4}-T_{\text {amb }}^{4}\right)\left(1-F_{12}\right)
\end{gathered}
$$

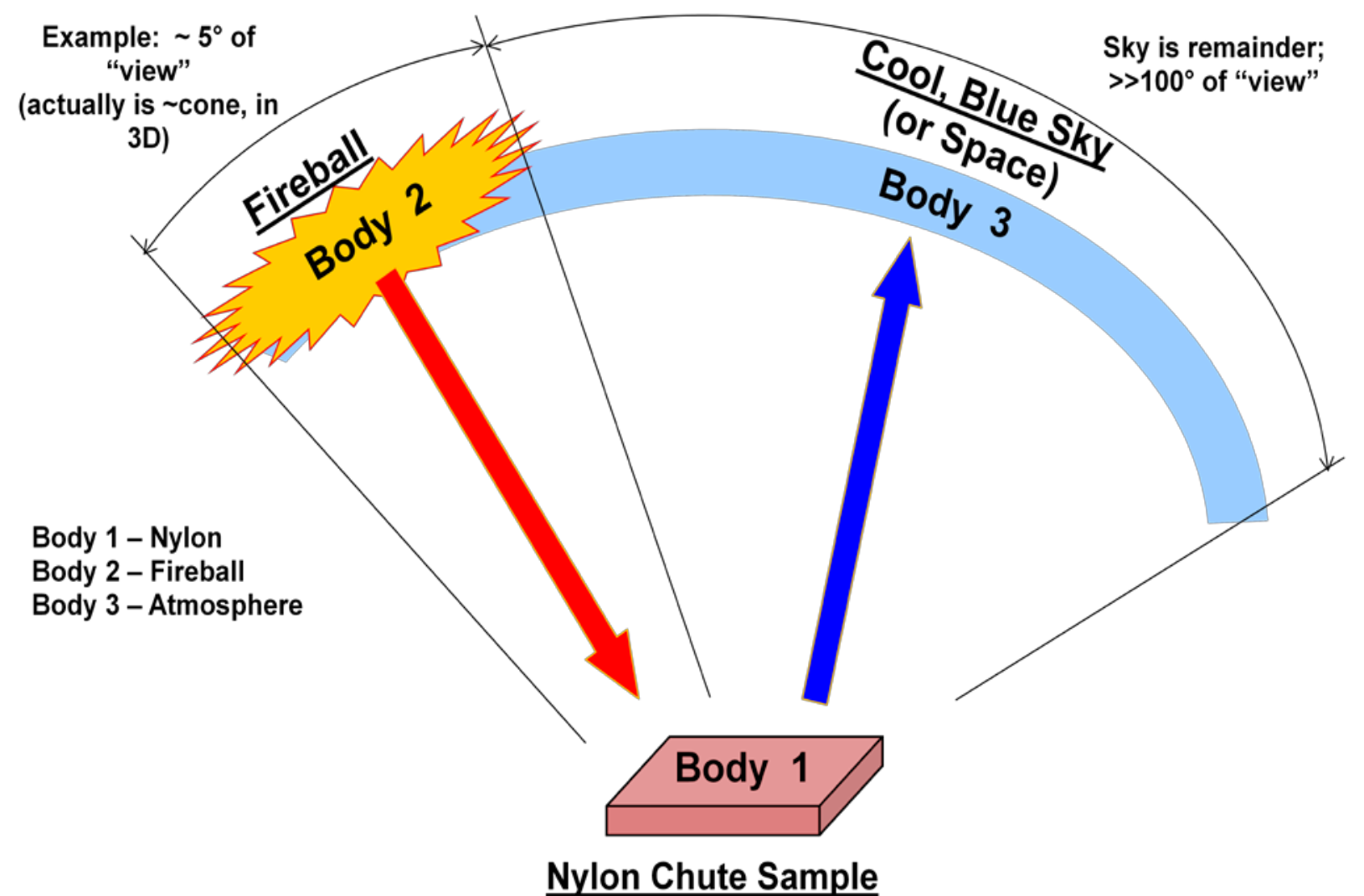

Figure 1. Diagram of Thermal Problem

The system has two equations, Eq. (4) and Eq. (5), and four unknowns: $q_{i n}, q_{\text {out }}, T_{\text {nylon }}$, and $F_{12}$. Since the goal is to create a temperature profile of the nylon, $\mathrm{T}_{\text {nylon }}$ will have an initial condition applied based on the situation. This 
leaves three unknowns, meaning $F_{12}$ will have to be solved for outside the heat flux equations. This is accomplished by starting with the generic equation for a two body view factor:

$$
F_{12}=\frac{1}{A_{1}} \iint \frac{\cos \theta_{1} \cos \theta_{2}}{\pi D^{2}} d A_{1} d A_{2} \text { (Ref. 4) }
$$

Here $A_{1}$ is the surface area of body $1, A_{2}$ is the surface area of body $2, \theta_{1}$ is the angle between normal vector of $\mathrm{A}_{1}$ and $\vec{D}, \theta_{2}$ is the angle between normal vector of $\mathrm{A}_{2}$ and $\vec{D}$, and $\mathrm{D}$ is the magnitude of the distance between $\mathrm{A}_{1}$ and $A_{2}$. An illustration supporting Eq. (6) can be seen in Fig. 2.

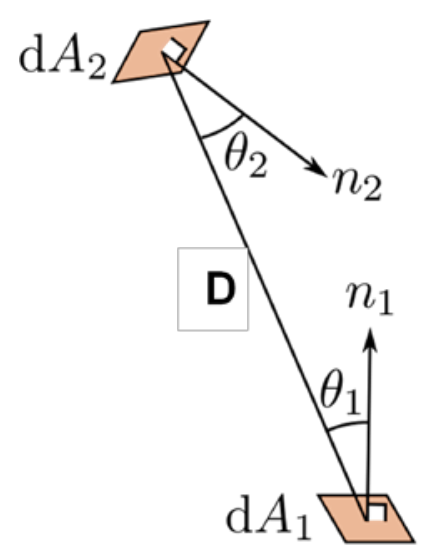

Figure 2. Illustration of $\mathbf{F}_{12}$

Equation (6) can be integrated to:

$$
F_{12}=\frac{1}{A_{1}}\left(\frac{\cos \theta_{1} \cos \theta_{2}}{\pi D^{2}}\right) A_{1} A_{2}
$$

Now assume that $A_{1}$ is a parachute segment with the normal vector pointed toward $A_{2}$. Only a segment of the parachute is analyzed, because even if only one section is degraded, the entire parachute system is considered failed. Assume $\mathrm{A}_{2}$ is the cross section or projected area of a spherical propellant debris piece of radius $\mathrm{r}$. Figure 3 is an illustration of $\mathrm{F}_{12}$ with these assumptions applied.
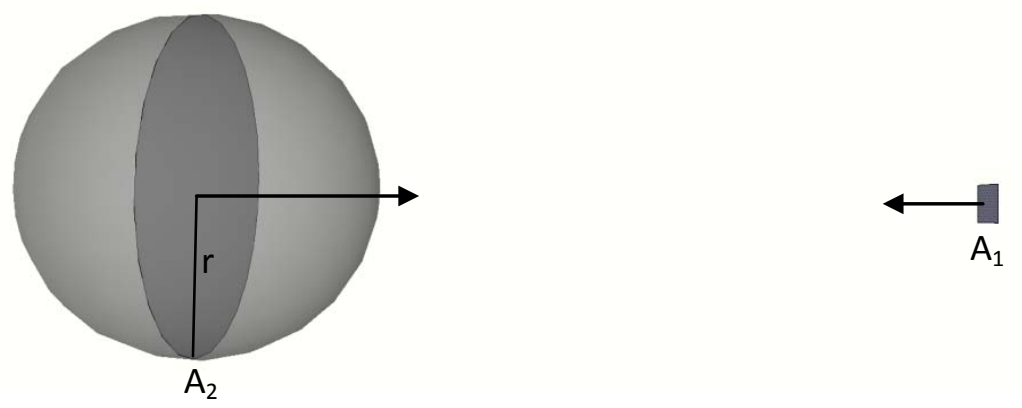

Figure 3. Illustration of $F_{12}$ with Assumptions

Equation (7) will then reduce to: 


$$
F_{12}=\frac{\cos 0 \cos 0}{\pi D^{2}} \pi r^{2}=\frac{r^{2}}{D^{2}}
$$

The reduction of Eq. (8) implies that the view factor is only dependent on the size of the debris and the distance of the debris from the parachutes. $F_{12}$ is the view factor of only one debris piece to the parachutes; the view factor of all the debris pieces to the parachutes is still needed. I assumed that all the propellant burns at the same constant temperature $-4000^{\circ} \mathrm{F}$ - and that there is no heat transfer between the debris pieces, meaning we can use the summation rule $-\left(\mathrm{F}_{1 \mathrm{~d} 1}+\mathrm{F}_{1 \mathrm{~d} 2}+\mathrm{F}_{1 \mathrm{~d} 3}+\mathrm{F}_{1 \mathrm{~d} 4}+\ldots\right)+\mathrm{F}_{13}=1$, where $\mathrm{F}_{1 \mathrm{~d} 1}$ is the view factor of body 1 to debris piece $1, \mathrm{~F}_{1 \mathrm{~d} 2}$ is the view factor of body 1 to debris piece 2, etc - to obtain the $F_{12}$ variable in Eq. (4) and Eq. (5).

Now that the view factors can be calculated, Eq. (4) and Eq. (5) can be used to calculate the net energy acting on the nylon. Multiply Eq. (4) and Eq. (5) by the area of nylon $\left(\mathrm{A}_{1}\right)$ to obtain the energy equations for the nylon. The net energy on the nylon is then calculated by taking the energy emitted by the nylon and subtracting it from the energy absorbed by the nylon:

$$
\begin{gathered}
Q_{\text {in }}=\varepsilon \sigma\left(T_{\text {fireball }}^{4}-T_{\text {nylon }}^{4}\right) F_{12} A_{1} \\
Q_{\text {out }}=\varepsilon \sigma\left(T_{\text {nylon }}^{4}-T_{\text {amb }}^{4}\right)\left(1-F_{12}\right) A_{1} \\
Q_{\text {net }}=Q_{\text {in }}-Q_{\text {out }}
\end{gathered}
$$

The net energy can then be used to calculate the change in temperature:

$$
\Delta T=\frac{Q_{\text {net }}}{c \rho_{N} A_{1}} \text { (Ref. 4) }
$$

For each time step, the delta temperature is applied to the previous parachute temperature. The result is a parachute temperature profile along the trajectory. An example can be seen in Fig. 5 or Fig. 6.

\section{Simulations}

The methodology was written into a MATLAB script. The required user inputs are the distance of the debris from the CM and the mass of the debris pieces, both at different time steps. The initial temperature of the parachute was conservatively set to $70^{\circ} \mathrm{F}(294 \mathrm{~K})$. The debris piece mass is used to calculate the spherical dimensions of each piece. The parachute temperature calculator employs the methodology detailed in Section III. The output is a parachute temperature profile. Figure 4 displays this simulation process.

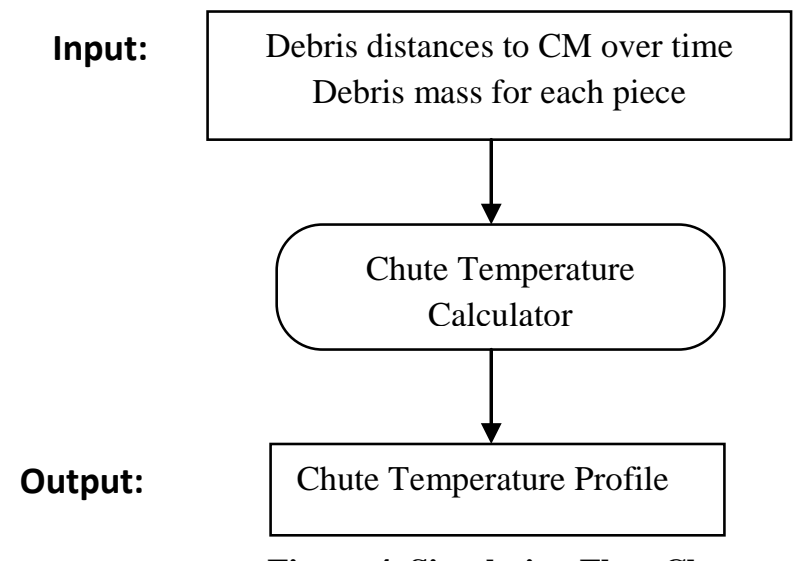

Figure 4. Simulation Flow Chart 


\section{Results}

Two abort cases were run with the Chute Temperature Calculator, one when the launch vehicle reaches Mach 1 ( $\sim 4$ sec MET) and one when it reaches Max Q ( 60 sec MET). Figure 5 below displays the temperature and minimum distance profiles for an abort at Mach 1.
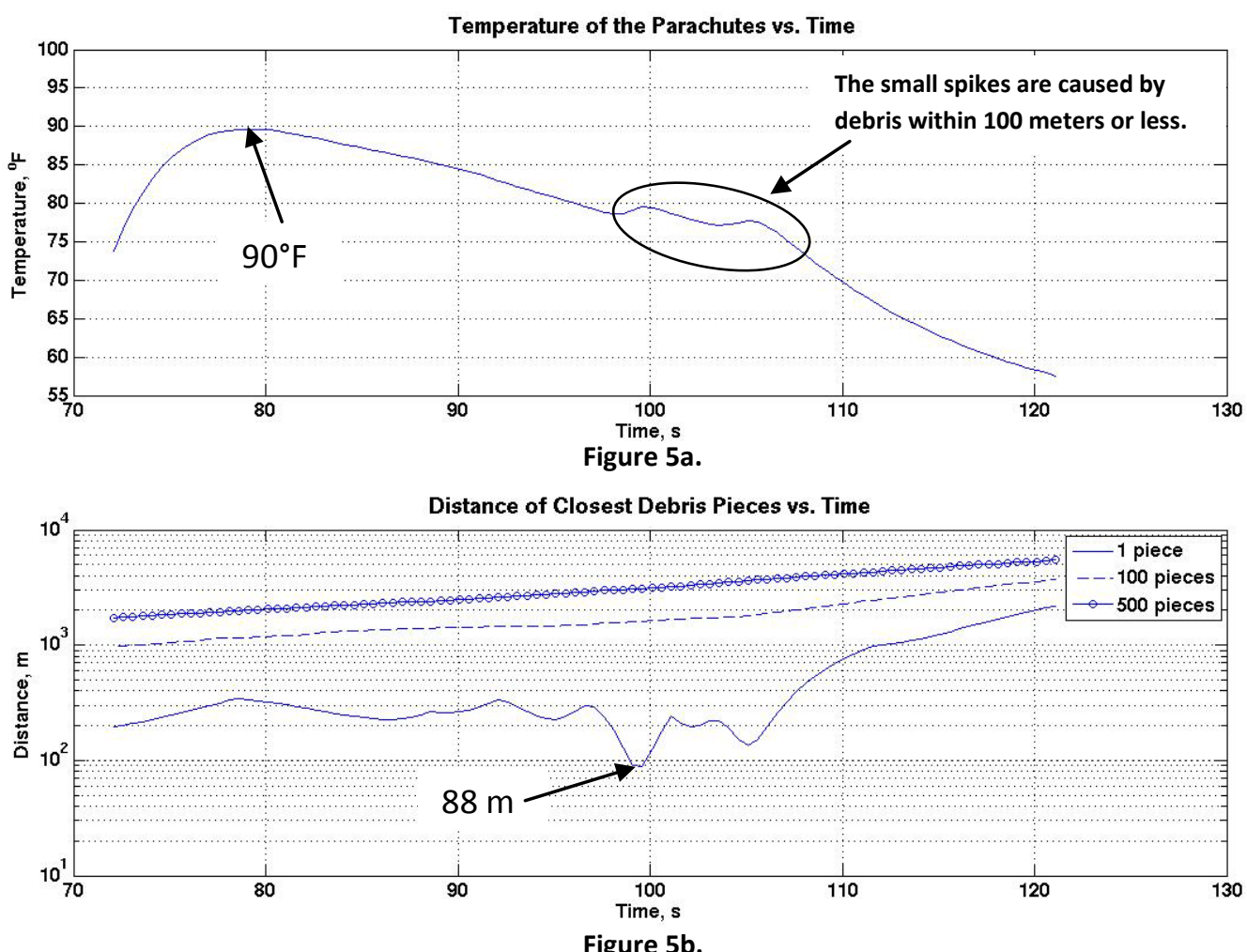

Figure 5. Abort at Mach 1 Temperature Profile (a) and Distance of Closest Pieces (b).

The first temperature increase in Fig. 5 a), from $72 \mathrm{~s}$ to $80 \mathrm{~s}$, was caused by a large number of debris pieces passing within approximately $200 \mathrm{~m}$ to $2000 \mathrm{~m}$ of the CM. The maximum temperature seen for the trajectory was $90^{\circ} \mathrm{F}$ and caused by the first temperature increase. The circled temperature spikes were caused by one or more debris pieces passing within $100 \mathrm{~m}$ of the CM. The relation between pieces passing close to the $\mathrm{CM}$ and a temperature spike can be seen by comparing Fig. 5 (a) and (b) at a selected time - a large downward spike seen in the closest debris piece profile correlates to an upwards spike in the temperature profile. The closest debris piece from this trajectory was $88 \mathrm{~m}$. For this case, the nylon failure temperature limit of $150^{\circ} \mathrm{F}$ was not reached. Figure 6 shows the results for the abort at Max Q. 


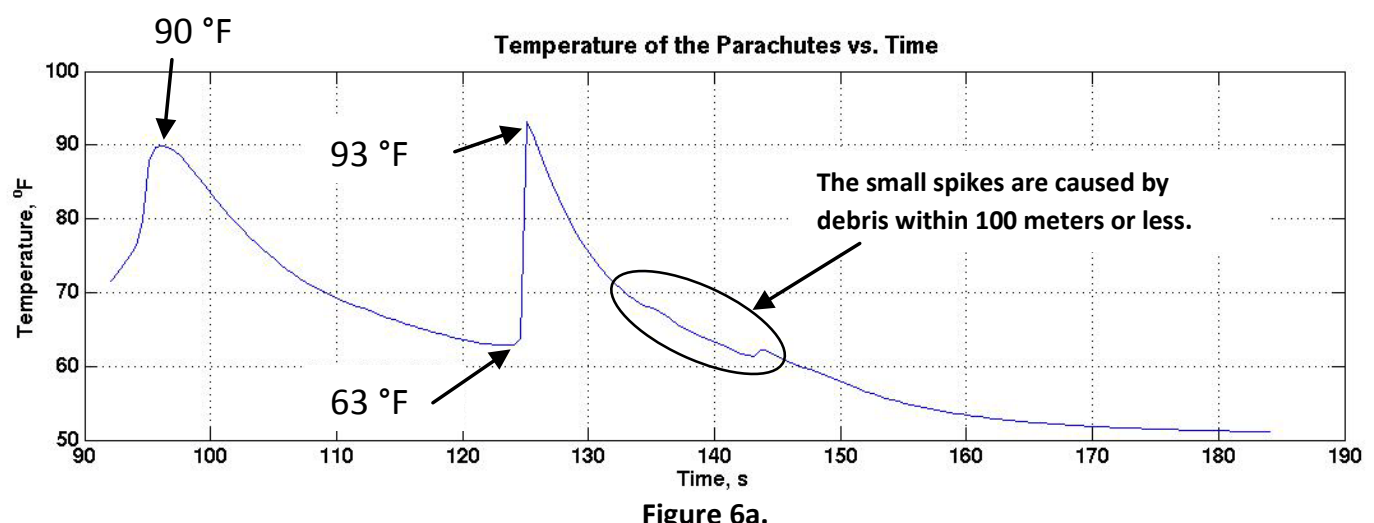

Figure 6a.

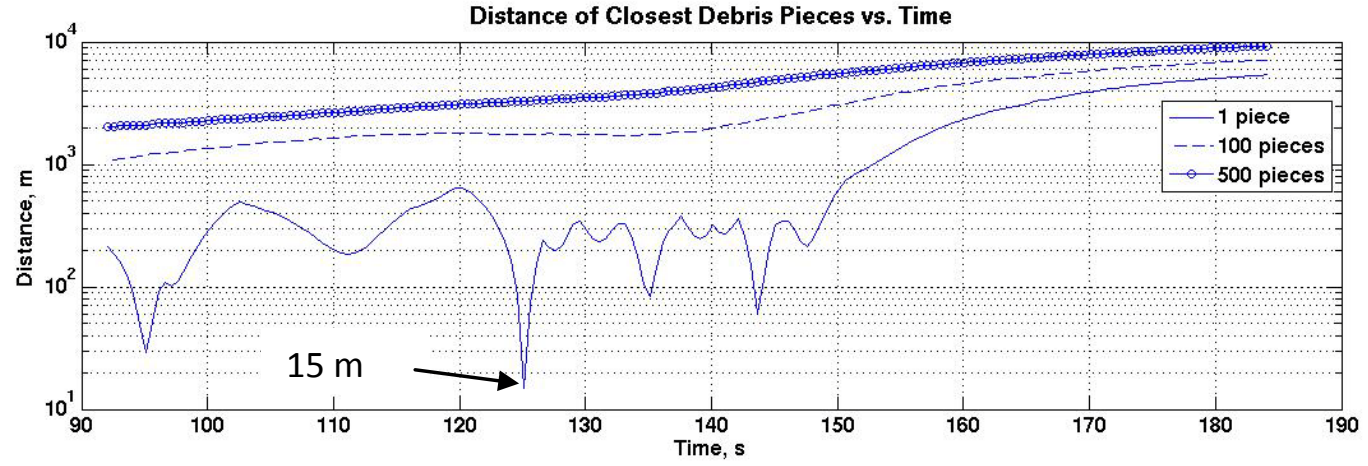

Figure 6b.

Figure 6. Abort at Max Q Temperature Profile (a) and Distance of Closest Pieces (b).

The first temperature increase in Fig. 6 (a), from $92 \mathrm{~s}$ to $97 \mathrm{~s}$, was caused by a large number of debris pieces passing within the approximate range of $200 \mathrm{~m}$ to $2000 \mathrm{~m}$. The first temperature spike, at $125 \mathrm{sec}$, was caused by a single debris piece flying within $14.8 \mathrm{~m}$ of the CM and only took $1 \mathrm{~s}$ to occur. The other smaller spikes were caused by a few pieces getting within $100 \mathrm{~m}$ of the parachute. For this case, the nylon failure temperature limit of $150^{\circ} \mathrm{F}$ was not reached.

Even though the Mach 1 and Max Q cases evaluated did not result in a thermal failure of the parachutes, there still exists a probability of the parachute temperature reaching the nylon failure limit for other debris field configurations. These two cases also demonstrate the risk that large temperature increases can occur in a short amount of time.

\section{Conclusions}

These two cases indicate there is a possibility of the temperature profile reaching the nylon failure temperature, if one or two pieces get too close to the CM. Only two cases were run and the results do not represent the full spectrum of possible debris field configurations. From these two cases I observed that the possibility exists for large temperature increases in a short amount of time, meaning that for a different debris field configuration and dispersed abort trajectory, a failure could occur. A set of dispersed abort trajectories with dispersed debris field configurations should be analyzed using the developed thermal methodology; however a Monte Carlo of this scale is very computationally intensive, and was not performed here due to the limited computational resources available to the author. This additional work would be used to calculate the probability of a thermal limit violation for the parachutes.

\section{Acknowledgments}

The author wishes to thank Sean Stapf and Ken Gee for their help with developing the methodology, Mary Jane O'Rourke for providing the constants and values used in the simulations and Stephen Miller for reviewing the finalized methodology and providing verification of assumptions. 


\section{References}

${ }^{1}$ Chapman, Alan J., Heat Transfer, $4{ }^{\text {th }}$ Ed., Macmillan, New York, 1984, Chap 11.

${ }^{2}$ Reynolds, William C., and Perkins, Henry C., Engineering Thermodynamics, McGraw-Hill, New York, 1977, pp. 576-580.

${ }^{3}$ Incropera, Frank P., and DeWitt, David P., Fundamentals of heat and Mass Transfer, $5^{\text {th }}$ ed., John Wiley \& Sons, New York, 2002, Chaps 12, 13.

${ }^{4}$ Avallone, Eugene A., and Baumeister, Theodore, III, Marks' Standard Handbook for Mechanical Engineers, $10^{\text {th }}$ Ed., McGraw-Hill, New York, 1996, pp. 4-63, 4-64, 4-65. 


\title{
First Stage Solid Propellant Multiply Debris Thermal Analysis
}

\author{
Ben Toleman
}




\section{Outline}

\section{- Introduction}

- Method

- Simulation

- Conclusion 


\section{Introduction}

- A solid rocket stage on a launch vehicle can create a thermal radiation hazard for an aborting crew module.

- For vehicles launched from the Eastern Range at Cape Canaveral, the Air Force requires capability from the ground to terminate thrust for launch vehicle on an errant trajectory in order to prevent that vehicle from traversing over land and putting the public at risk.

- Because solid propellant vehicles are incapable of being shut down, they require a Flight Termination System (FTS) that, when activated, destroys the vehicle and freezes the vehicle's impact point.

- Detonation of Constellation's Ares I launch vehicle results in thousands of debris fragments, the majority of which are first stage solid rocket propellant fragments, which pose a threat to the aborted crew module (CM).

- The risk of debris strikes in first stage abort scenarios have been studied in depth by the Cx Program. However, a secondary debris concern exists - the thermal effects of burning solid rocket propellant on the CM, and specifically on the parachute system.

- I performed an independent analysis to determine the thermal effects of high temperature debris on the CM parachute system.

- From this analysis I developed a process to assess those thermal.

- Analyzed the cumulative thermal effects on the parachutes to assess risk of parachute failure.

- Integrated the temperature over time from drogue chute deploy. 


\section{Assumptions}

- First Stage propellant debris

- spherical shape

- radiate as black bodies

- The nylon chutes have an emissivity of 0.899 .

- The chutes failure temperature is $339^{\circ} \mathrm{K}\left(150^{\circ} \mathrm{F}\right)$.

- Conservation of Energy

- Debris density is $\mathbf{0 . 0 6 5} \mathrm{lbm} / \mathrm{in} \wedge$ 3.

- Ambient Temperature is $283^{\circ} \mathrm{K}\left(50^{\circ} \mathrm{F}\right)$.

- The debris burns at a constant $4000^{\circ} \mathrm{F}(2478 \mathrm{~K})$ through the entire abort trajectory.

- There is no heat transfer between debris, therefore all debris pieces are at the same temperature 


\section{Method - View Factor Illustration}

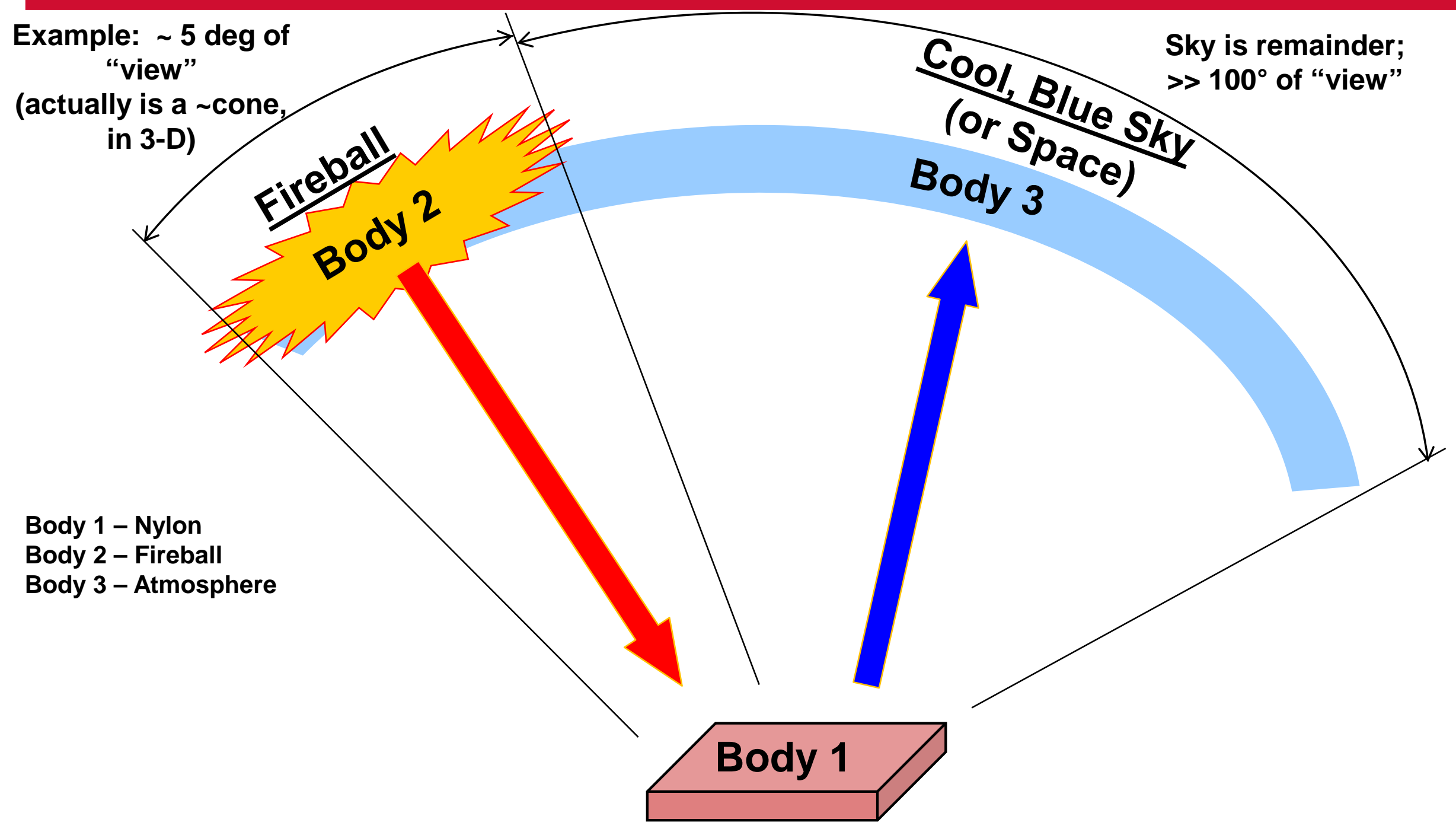

Nylon Chute Sample

( 1" square "postage stamp") 


\section{Method}

- The foundation of this methodology is based on the Stefan-Boltzmann Law:

$$
q=\varepsilon \sigma T^{4}
$$

- The problem is constructed as a three body system, as depicted in the next slide. Two equations were written to represent the heat flux imparted to the nylon from the fireball, and the heat flux radiated out from the nylon to the sky:

$$
\begin{aligned}
& q_{\text {in }}=\varepsilon \sigma\left(T_{\text {fireball }}^{4}-T_{\text {nylon }}^{4}\right) \\
& q_{\text {out }}=\varepsilon \sigma\left(T_{\text {nylon }}^{4}-T_{\text {amb }}^{4}\right)
\end{aligned}
$$

- The two equations above are multiplied by a View Factor to account for the percent of radiation transfer. The summation rule, $F_{12}+F_{13}=1$, is applied to consolidate variables.

$$
\begin{aligned}
q_{\text {in }} & =\varepsilon \sigma\left(T_{\text {fireball }}^{4}-T_{\text {nylon }}^{4}\right) F_{12} \\
q_{\text {out }} & =\varepsilon \sigma\left(T_{\text {nylon }}^{4}-T_{\text {amb }}^{4}\right) F_{13} \rightarrow \\
q_{\text {out }} & =\varepsilon \sigma\left(T_{\text {nylon }}^{4}-T_{\text {amb }}^{4}\right)\left(1-F_{12}\right)
\end{aligned}
$$




\section{Method - Continued}

- $F_{12}$ is defined as the "fraction of radiation leaving surface 1 that is intercepted by surface $2 "$ ".

$$
F_{12}=\frac{1}{A_{1}} \int_{A_{1}} \int_{A_{2}} \frac{\cos \left(\theta_{1}\right) \cos \left(\theta_{2}\right)}{\pi D^{2}} d A_{1} d A_{2}^{4}
$$

- Integrated: $F_{12}=\frac{1}{A_{1}}\left(\frac{\cos \left(\theta_{1}\right) \cos \left(\theta_{2}\right)}{\pi D^{2}}\right) A_{1} A_{2}$

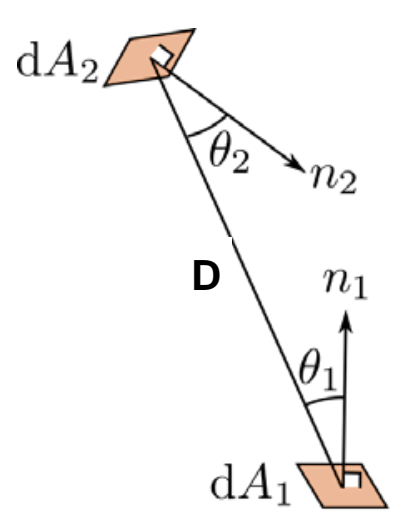

- For purposes of this analysis, assume:

- $A_{1}$ is the parachute, with the normal vector pointed toward $A_{2}$.

- $A_{2}$ is the cross section or projected area of a spherical propellant debris piece of radius $r$.

$$
\begin{aligned}
& A_{2}=\pi r^{2} \\
& \theta_{1}=\theta_{2}=0^{\circ} \quad F_{12}=\frac{\cos (0) \cos (0)}{\pi D^{2}} \pi r^{2} \Rightarrow \frac{r^{2}}{D^{2}}
\end{aligned}
$$




\section{Method - Continued}

- The emissive power equations are multiplied by $A_{1}$ to get the energy equations of the nylon:

$$
\begin{aligned}
& Q_{\text {in }}=\sigma\left(T_{\text {freball }}^{4}-T_{\text {nylon }}^{4}\right) F_{12} A_{1} \\
& Q_{\text {out }}=\sigma\left(T_{\text {nylon }}^{4}-T_{\text {amb }}^{4}\right)\left(1-F_{12}\right) A_{1}
\end{aligned}
$$

- Then subtract $Q_{\text {in }}$ from $Q_{\text {out }}$ to get the net energy, $Q_{\text {net }}$

$$
Q_{\text {net }}=Q_{\text {in }}-Q_{\text {out }}
$$

- The net energy can then be used to calculate the change in temperature :

$$
\Delta T=\frac{Q_{\text {net }}}{c \rho_{N} A_{1}}
$$




\section{Simulation}

- The methodology was written into a MATLAB script.

- Analyzed the cumulative effects of the changing temperature on the parachutes. Integrated the temperature over time from drogue chute deploy.

- The required user inputs were the distance of the debris from the $\mathrm{CM}$ and the mass of the debris pieces, both at different time steps.

- The debris piece mass is used to calculate the spherical dimensions of each piece.

- The methodology detailed in the previous slides was used to create a parachute temperature profile. 


\section{Abort at Mach 1}
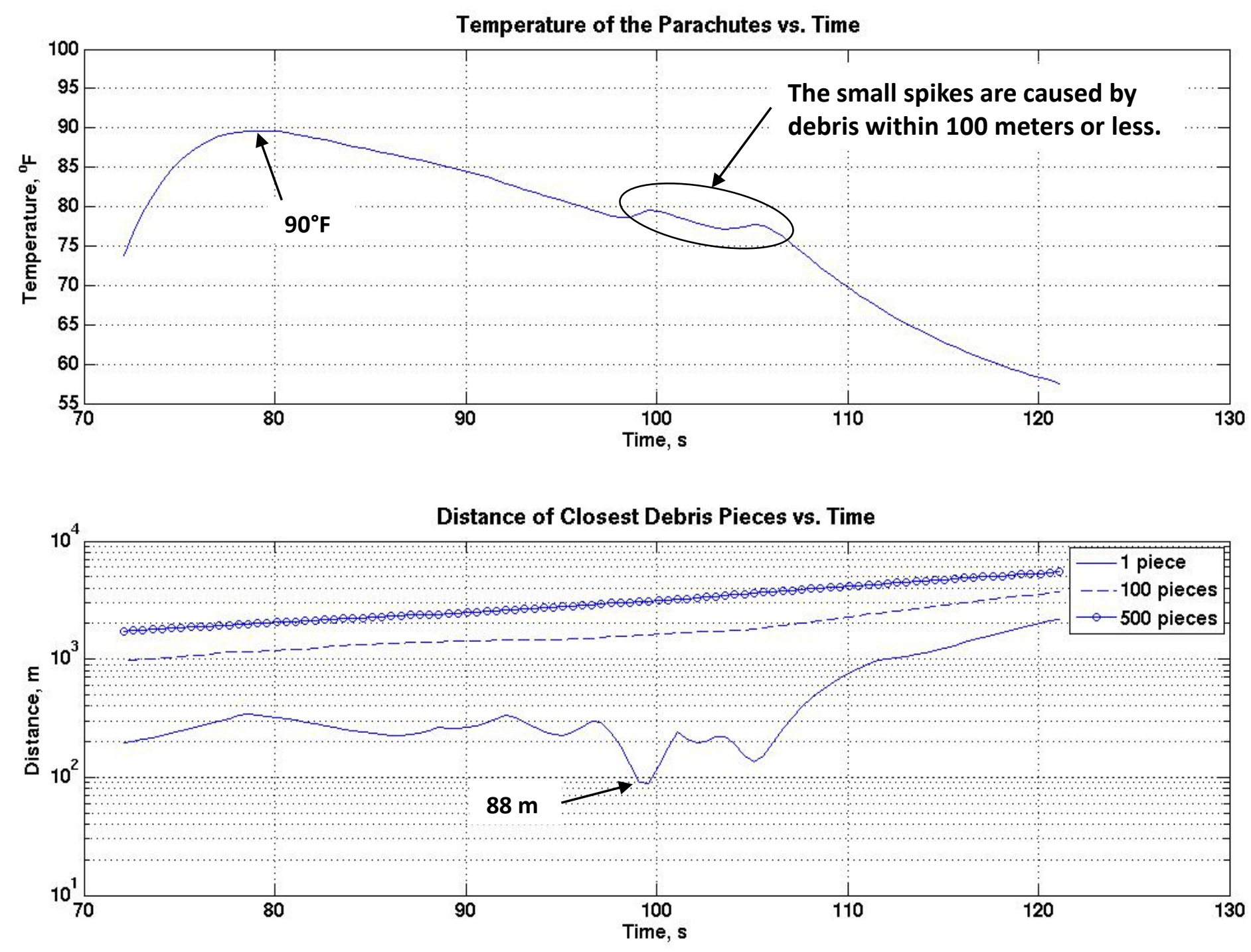


\section{Abort at Max Q}
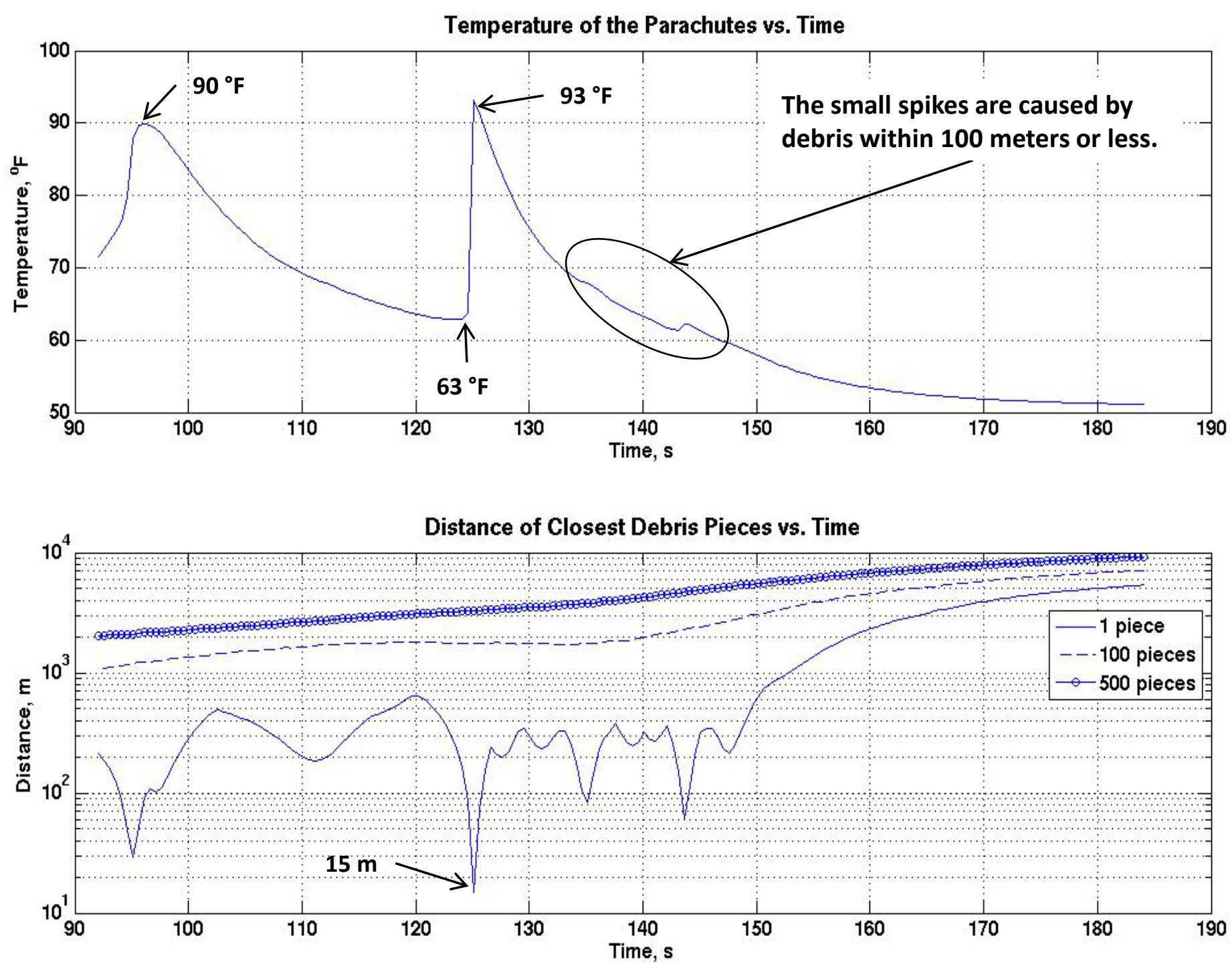


\section{Conclusions}

- From the two cases run, it was observed that the possibility exists for large temperature increases in a short amount of time, meaning that for a different debris field configuration and dispersed abort trajectory, a failure could occur.

- The temperature profile is driven more by a small number of debris pieces passing close by (within $100 \mathrm{~m}$ ) than by the general population of debris further away.

- These two cases indicate there is a possibility of the temperature profile reaching the nylon failure temperature, if one or two pieces get too close to the CM.

- A set of dispersed abort trajectories with dispersed debris field configurations should be analyzed using the developed thermal methodology; however a Monte Carlo of this scale is very computationally intensive, and was not performed here due to the limited computational resources available to the author. This additional work would be used to calculate the probability of a thermal limit violation for the parachutes. 


\section{References}

1. "Heat Transfer", $4^{\text {th }}$ Edition; Alan J. Chapman, 1984.

2. "Engineering Thermodynamics"; William C. Reynolds and Henry C. Perkins, 1977.

3. "Fundamentals of Heat and Mass Transfer", $5^{\text {th }}$ Edition; Frank P. Incropera and David P. DeWitt, 2002.

4. "Marks' Standard Handbook for Mechanical Engineers", 10 $10^{\text {th }}$ Edition; Eugene A. Avallone and Theodore Baumeister III, 1996. 


\section{Acknowledgments}

- The author wishes to thank Sean Stapf and Ken Gee for their help with developing the methodology, Mary Jane O'Rourke for providing the constants and values used in the simulations and Stephen Miller for reviewing the finalized methodology and providing verification of assumptions. 